\title{
Conhecimento ecológico da espécie de Mangue de Botão (Conocarpus Erectus): o passeio turístico no Parque Nacional de Jericoacoara - Ceará
}

\author{
Ecological knowledge of the species of Mangrove Button (Conocarpus Erectus): the tour in the \\ National Park of Jericoacoara - Ceará \\ Conocimiento ecológico de la especie de Botón de Manglar (Conocarpus Erectus): el tour en el \\ Parque Nacional de Jericoacoara - Ceará
}

Recebido: 13/05/2021 | Revisado: 19/05/2021 | Aceito: 02/09/2021 | Publicado: 05/09/2021

\author{
Rosaline Ferreira de Oliveira \\ ORCID: https://orcid.org/0000-0001-8057-1951 \\ Instituto Federal de Educação, Ciência e Tecnologia do Ceará, Brasil \\ E-mail: rosaline30@gmail.com \\ Francisca Rosilane Oliveira \\ ORCID: https://orcid.org/0000-0003-4493-4510 \\ Instituto Federal de Educação, Ciência e Tecnologia do Ceará, Brasil \\ E-mail: rosilaneoliveira2@gmail.com \\ Alisandra Cavalcante Fernandes de Almeida \\ ORCID: https://orcid.org/0000-0002-7066-1504 \\ Instituto Federal de Educação, Ciência e Tecnologia do Ceará, Brasil \\ E-mail:alisandra.cavalcante@ifce.edu.br
}

\begin{abstract}
Resumo
O turismo na crescente sustentável age no experimento de reduzir os principais impactos referente a conduta importuna de viajantes e guias de turismo, ação capaz de gerar desequilíbrio no meio ambiente e nas populações receptoras, populações que se encontram inseridas nesse contexto. A pesquisa, portanto, objetivou aferir o entendimento ecológico dos guias (motoristas) sobre a espécie (Conocarpus erectus) e verificou se a percepção interfere na maneira de conservação da espécie. Seguindo os procedimentos metodológicos deste estudo, foram aplicados na praia do Preá, município de Cruz/CE, 30 questionários, com os guias (motoristas) vinculados à Cooperturpreá. Ao aplicar os questionários, nosso principal objetivo foi traçar o perfil dos guias (motoristas) e aferir o nível de conhecimento ecológico sobre a vegetação do Parque, mais especificamente sobre o Mangue de Botão (Conocarpus erectus), a Árvore da Preguiça. A abordagem utilizada para a coleta dos dados foi quanti-qualitativa. Esta pesquisa possibilitou verificar que os guias (motoristas), em sua grande maioria, de fato tem um entendimento sobre a espécie Mangue de Botão (Conocarpus erectus) ainda que não se tenham o domínio dos termos técnicos, apresentam conhecimento ecológico sobre a espécie, demonstram conhecimento sobre o ciclo de vida, a floração e a frutificação da espécie, contudo recomenda-se investigar com mais profundidade esse conhecimento ecológico sobre a espécie em estudo.
\end{abstract}

Palavras-chave: Turismo sustentável; Árvore da preguiça; Conhecimento ecológico; Cooperativa; Passeio turístico.

\begin{abstract}
Tourism in the sustainable crescent acts in an experiment to reduce the main impacts related to the intrusive behavior of travelers and tour guides, an action capable of generating an imbalance in the environment and in the receiving populations, populations that are inserted in this context. The research, therefore, aimed to assess the ecological understanding of the guides (drivers) about the species (Conocarpus erectus) and verified whether the perception interferes in the manner of conservation of the species. Following the methodological procedures of this study, 30 questionnaires were applied at Praia do Preá, in the city of Cruz/CE, with guides (drivers) linked to Cooperturpreá. When applying the questionnaires, our main objective was to profile the guides (drivers) and assess the level of ecological knowledge about the Park's vegetation, more specifically about the Button Mangrove (Conocarpus erectus), the Sloth Tree. The approach used for data collection was quantitative and qualitative. This research made it possible to verify that the guides (drivers), for the most part, in fact have an understanding of the Mangue de Botón (Conocarpus erectus) species, although they do not have mastery of technical terms, they have ecological knowledge about the species, they demonstrate knowledge about the life cycle, flowering and fruiting of the species, however it is recommended to further investigate this ecological knowledge about the species under study.
\end{abstract}

Keywords: Sustainable tourism; Sloth tree; Ecological knowledge; Cooperative; Tour. 


\begin{abstract}
Resumen
El turismo en la media luna sostenible actúa en un experimento para reducir los principales impactos relacionados con el comportamiento intrusivo de viajeros y guías turísticos, acción capaz de generar un desequilibrio en el medio ambiente y en las poblaciones receptoras, poblaciones que se insertan en este contexto. La investigación, por tanto, tuvo como objetivo evaluar la comprensión ecológica de los guías (conductores) sobre la especie (Conocarpus erectus) y verificó si la percepción interfiere en la forma de conservación de la especie. Siguiendo los procedimientos metodológicos de este estudio, se aplicaron 30 cuestionarios en Praia do Preá, en la ciudad de Cruz / CE, con guías (conductores) vinculados a Cooperturpreá. Al aplicar los cuestionarios, nuestro principal objetivo fue perfilar a los guías (conductores) y evaluar el nivel de conocimiento ecológico sobre la vegetación del Parque, más específicamente sobre el Manglar Botón (Conocarpus erectus), el Árbol Perezoso. El enfoque utilizado para la recopilación de datos fue cuantitativo y cualitativo. Esta investigación permitió verificar que los guías (conductores), en su mayor parte, de hecho tienen un conocimiento de la especie Mangue de Botón (Conocarpus erectus), aunque no dominan los términos técnicos, tienen conocimientos ecológicos sobre la especie, demuestran conocimiento sobre el ciclo de vida, floración y fructificación de la especie, sin embargo se recomienda investigar más a fondo este conocimiento ecológico sobre la especie en estudio.
\end{abstract}

Palabras clave: Turismo sostenible; Árbol de pereza; Conocimiento ecológico; Cooperativa; Paseo turístico.

\title{
1. Introdução
}

O turismo na crescente sustentável age no experimento de reduzir os principais impactos referente a conduta importuna de viajantes e guias de turismo, ação capaz de gerar desequilíbrio no meio ambiente e nas populações receptores, populações que se encontram inseridas nesse contexto. Para existir crescimento da atividade turística de forma adequada, devese realizar algumas ações, para favorecer a conservação da cultura e das características das comunidades receptoras, e para a além disso; encorajar boas práticas no decorrer da viagem, bem como conservar a paisagem de modo sustentável, dessa forma, tornar possível a expansão do funcionamento das ações turísticas sem comprometer a capacidade de atender às futuras gerações que buscam a expansão para o melhoramento desta atividade de forma ecologicamente equilibrada. (Barbosa; Perinotto, 2011).

Nessa perspectiva, a visão Etnoecológica pode auxiliar como instrumento para a biologia da preservação, em questões que envolvam apropriação e/ou exploração humanas, podendo alinhar a troca de conhecimentos com comunidades locais; assimilando sua percepção ecológico local; para o entendimento de suas relações, traçando estratégias sobre o uso dos recursos naturais; bem como as questões ecológicas pertinentes; as consequência e alterações ambientais (Ternes, 2011).

Nesse sentido, a espécie Conocarpus erectus conhecida popularmente como Árvore da Preguiça, insere-se como atrativo turístico para os visitantes do Parque Nacional de Jericoacoara.

O parque oferece atrativos turísticos que podem ser visitados durante a estadia do visitante, e uma dos produtos ofertados aos visitantes, é um passeio para conhecer as belezas naturais do local, o passeio é realizado em grupo ou individual, a incursão é realizado em bugies, ou caminhonetes tracionadas, onde o próprio motorista, assume a função de "guia de turismo", e passa seu conhecimento sobre a paisagem visitada. No decorrer do percurso, uma das paradas obrigatórias é para observar a Árvore da Preguiça (ICMBIO, Parque Nacional de Jericoacoara, 2018).

Segundo a Portaria 500, de setembro de 2019, que atualiza e aprova o Plano de Ação Nacional para a Conservação das Espécies Ameaçadas e de Importância Socioeconômica do Ecossistema Manguezal (PAN Manguezal), que contempla 20 táxons ameaçados de extinção, dentre os quais está incluída a espécie Conocarpus erectus, conhecida popularmente como Mangue de Botão.

Este trabalho foi motivado pela inquietude relativa às pesquisas e percepções associado aos entendimentos biológicos sobre espécies nativas da extensão local, que eventualmente estão correndo risco de serem extintas, e para além disso está pesquisa visa tornar efetiva a colaboração para o desenvolvimento de pesquisas futuras, pois são poucos os trabalhos que investigam a problemática relacionada entre a visitação e seu impacto na flora local. Bem como, os critérios desta pesquisa procuraram reorientar a participação acadêmica para a compreensão de adversidades e melhorias de questões sociais atreladas 
ao ecossistema em questão.

A pesquisa, portanto, objetivou aferir o entendimento ecológico dos guias (motoristas) sobre a espécie (Conocarpus erectus) e verificou se percepção interfere na maneira de conservação da espécie, elencando os seguintes objetivos específicos: (1) Verificar aspectos sociodemográficos dos guias (motoristas) que realizam o passeio turístico; (2) Avaliar qual a motivação dos turistas para realizar o passeio na árvore da preguiça; (3) Analisar a compreensão ambiental e a satisfação turística associada à vivência da visitação.

\subsection{Turismo Sustentável: Ação voltada para a percepção ambiental na vertente da visitação}

De La Torre (1992), salienta que o turismo vem se destacando como um fenômeno social onde se consiste principalmente no deslocamento voluntário e temporário de indivíduos que, por alguns motivos de recreação, descanso, cultura ou saúde, saem do seu local de residência habitual para outro, no qual não exercem nenhuma atividade lucrativa nem remunerada, gerando múltiplas interrelações de importância social, econômica e cultural. (De la Torre,1992, p. 19).

Segundo Irving (2002), o turismo sustentável pressupõe conceituar princípios baseados na valorização ética, objetivando a democratização para gerar mais possibilidades e vantagens, e para além disso tornar uma referência de elaboração de projetos no qual objetiva a busca por colaboradores que mantenham o comprometimento de propor um turismo sustentável aberta a sociedade.

Ao inserir as dimensões da sustentabilidade tenta-se preencher algumas lacunas encontradas em torno do conceito, em virtude da acepção generalizada permitem-se inúmeros desvirtuamentos e considerações que sempre tendem para o viés econômico. De modo, a consideração da sustentabilidade sob espectro destas três dimensões à fez mais clara e objetiva, entretanto ainda distante das necessidades e anseios da sociedade atual quando relacionam o conceito social, econômico e ambiental.

O estudo do turismo potencializa diferentes áreas do conhecimento, por isso, são várias as interpretações baseadas nas ações turística identificadas, a exemplo, os economistas, o estudam como atividade geradora de benefícios econômicos, e, os sociólogos, classificam como uma ação que envolve a interação social e troca cultural entre os indivíduos. Prática essa que vem sendo realizada por diversos especialistas, contribuindo consideravelmente na perspectiva de restauração e conservação de parques ecológicos que recebem o turismo como atividade sustentável. (BORGES, 2016).

\subsection{Mangue de Botão (Conocarpus Erectus)}

A terminologia mangue é usado para indicar um grupo paisagístico de árvores e arbustos de plantas, de clima tropical, advinda deste ecossistema estuarino conhecido como manguezal, e nesta extensão encontra- se espécies que habitam neste ecossistema a exemplo tem - se o Conocarpus erectus conhecida popularmente como "mangue de botão" esta espécie pertence à família Compretaceae podendo ser localizadas nas regiões costeiras tropicais e subtropicais do mundo (Teixeira, 2008).

Contudo é uma espécie nativa do Brasil e consegue, mesmo estando, efetivamente, em áreas tropicais, ser tolerante a uma imersão de habitats nos lugares onde é encontrada. Em linhas gerais o mangue de botão é um arbusto que apresenta 6 metros de altura suas flores são esverdeadas e na maioria das vezes apresenta casca de cor cinza ou marrom (Rodrigues Neto et al., 2018).

Giri e colaboradores (2008), salienta que os manguezais são áreas relevantes e que promove meios e serviços para as comunidades que se encontram inseridas neste contexto, desempenhando assim a geração de oportunidades em diversas linhagens do conhecimento a exemplo no econômico desenvolve um formidável papel, no ecológico favorece o equilíbrio ambiental.

Partindo desta perceptiva, no caminho da Praia do Preá localiza-se a espécie Mangue de Botão (Conocarpus erectus), 
localizado no Parque Nacional de Jericoacoara, a espécie cresceu à beira-mar e foi nomeada de árvore da Preguiça, devido à dificuldade que tinha em erguer seus galhos, pois é como se espécie estivesse deitada, e seus galhos se estendem por volta de 4 metros de distância da árvore. Tudo isto aconteceu devido aos fortes ventos que têm na praia e a árvore não teve força suficiente para se erguer novamente.

A espécie com localização à beira-mar induz o imaginário dos indivíduos, tornando assim um forte apelo como atrativo turístico para região, que compõe um dos serviços ofertados aos visitantes, o passeio da árvore da preguiça é realizado com bugies ou em caminhonetes tracionadas. Não se vê nada ao lado, a não ser dunas, o mar e a Árvore da Preguiça que se destaca na paisagem.

O Instituto Chico Mendes de Conservação da Biodiversidade - ICMBio (2018) salienta que a remoção de madeira não considera os níveis ou técnicas sustentáveis de extração e que dificilmente adota as orientações dos planos de manejo florestal, dados que constam nas leis de preservação ambiental.

Segundo a proposta de manejo do Parque Nacional de Jericoacoara, a vegetação é de crescimento reptante e a maior altura encontrada chega a 20 centímetros. Uma pequena parcela concentra-se perto da praia, local em que as plantas sofrem fortes pressões ambientais, que limitam, assim, seu crescimento. Apesar da pouca riqueza florística, esse ponto está em bom estado de preservação e relativamente bem preservado. Nas proximidades da margem esquerda da foz do Riacho Doce, a espécie Conocarpus erectus L. (Mangue de Botão) apresenta alguns indivíduos fora da área de buffer do ponto, demonstrando o deslocamento do riacho, que fica situado no litoral leste do Parque.

\subsection{Etnobiologia}

De forma mais objetiva, Martin (2001) diz que o prefixo etno é uma forma simplificada de dizer "esta é a maneira como os outros vêem o mundo", e sempre que esse prefixo anteceder ao nome de uma disciplina acadêmica, atrela-se aos pesquisadores no sentido de que estão em busca da percepção de uma determinada comunidade frente a um dado aspecto do conhecimento científico e/ou cultural vivenciados por ambos.

Desta forma etnobiologia surge através de percepções, conceitos e classificações feitas por comunidades que, na maioria das vezes, apresentam concepções de vivência e mundo diferentes das estabelecidas pelo saber científico elencando os saberes culturais são construindo e passado para comunidades futuras.

Contudo podendo ser classificada como uma área do pensamento etnobiológico que age no campo do entendimento habitual dos indivíduos, observando, na prática metodologias de como determinadas comunidades se comportam no âmbito que estão inseridas, ou seja, em sociedade. (Vayda; Rappaport, 1968; Berlin, 1973; Begossi, 1993)

Diante disso, a Etnobiologia apresenta grandes relevâncias, por alinhar o conceito científico com as práticas culturais, favorecendo a compreensão dos conhecimentos locais das comunidades tradicionais, que tem como foco principal o desenvolvimento de novas linhagem.

Neste contexto é que as associações de indivíduos se constituem na perspectiva de cooperação para acessar ao comércio turístico que se expande no local em que está inserido.

\subsection{Cooperativismo}

De acordo com a ideia sociológica é cabível afirmar que a "cooperação é uma forma de integração social e pode ser entendida como ação conjugada em que indivíduos se reúnem de modo formal ou informal, para alcançar o mesmo objetivo" (Pinho, 1966, p. 08).

Podemos entender o cooperativismo como um processo de produção, consumo e crédito que tem por alicerce as sociedades cooperativas, formadas com base no associativismo e na autogestão. Vários segmentos existentes apontam 
interação de empresas como grande avanço na economia do país (Mielke, 2010).

E para além disso o cooperativismo surge como uma estratégia universal, que se propõe preservar a unidade da doutrina e da filosofia partindo do princípio cooperativista, além de resguardar os interesses do cooperativismo pelo mundo" Sebrae (2009).

\subsection{Cooperativas vinculadas ao Parque Nacional de Jericoacoara/CE}

As cooperativas são designadas como uma coletividade civil de indivíduos e natureza jurídica próprias, sem atos lucrativos, não sujeita à falência, constituída para prestar serviços a seus associados, buscando atender às suas demandas sociais, econômicas e culturais. Os cooperados se juntam para desenvolver suas necessidades e agregar benefícios mútuo. Entretanto o ato de cooperar parte do princípio de unir forças entre seus associados que busca desenvolver práticas coletivas, pautadas em condutas e resultados que dificilmente seriam alcançáveis com proeza de forma individual (SEBRAE, 2009).

O Parque Nacional de Jericoacoara em sua extensão territorial tem parceiras com cooperativas credenciadas e legalizadas pelo Ministério do Turismo e cada cooperativa tem um presidente, com seus cooperados com a finalidade de atuar na condução dos visitantes. A saber as cooperativas são: a) COOPJERI 4X4 - Fretamento e Turismo Jericoacoara; b) COOPTUR PREÁ - Cooperativa de Transporte de Jericoacoara; c) COOPERJERI - Fretamento e Turismo; e d) COOPBJ Cooperativa dos Bugueiros de Jericoacoara.

As cooperativas citadas anteriormente participam ativamente na condução dos visitantes ao Parque Nacional de Jericoacoara, e um dos destinos é o passeio turístico realizado no litoral leste, onde se encontra o exemplar Mangue de Botão (Conocarpus erectus) conhecido popularmente como Árvore da Preguiça.

\section{Procedimentos Metodológicos}

Esta pesquisa configura-se de caráter exploratório, realizado através de pesquisa bibliográfica, e execução de questionários, entrevistas e análises no campo. O procedimento utilizado foi quanti-qualitativa, pois, segundo Minayo e Sanches (1993), ainda que tenham natureza diferenciada, ambas são complementares, o que facilita o entendimento da realidade social.

\section{1 Área de Estudo}

A pesquisa foi realizada nos municípios de Jijoca de Jericoacoara e Cruz, situados no estado do Ceará. Essas áreas de extensão têm parte do seu território classificada como área do Parque Nacional de Jericoacoara, localizado a 288 quilômetros de Fortaleza, no Ceará.

Para chegar ao PARNA de Jericoacoara existem três alternativas: Trilha da Lagoa Grande; Trilha da Praia do Preá; e Trilha do Mangue Seco. Os percursos não são pavimentados e, geralmente, utilizam-se veículos de tração ou bugies. Os veículos que cruzam os campos de dunas e as áreas de estuários, para chegar à Vila de Jericoacoara, estão organizados em quatro cooperativas.

As visitas à área de estudo serviram para identificação do ponto de interesse turístico. Foram aplicados questionários para obter informações sobre o conhecimento dos guias (motoristas) a respeito da espécie que é utilizada como atrativo turístico, bem como analisado o perfil socioeconômico dos guias (motoristas).

Para investigar a motivação e a satisfação dos visitantes, foram realizadas entrevistas, com o intuito de verificar qual a percepção ambiental e a satisfação relacionadas à experiência da visitação durante o passeio. 
Quanto aos aspectos éticos, esta pesquisa teve a aprovação do Comitê de Ética em Pesquisa do IFCE (CEP), e do Instituto Chico Mendes de Conservação da Biodiversidade (ICMBio - SISBio), além disso, foi usado o Termo de Consentimento Livre e Esclarecido (TCLE) no momento das entrevistas.

Entretanto, os dados coletados foram de uso único e exclusivo para a elaboração do Trabalho de Conclusão de Curso (TCC) apresentado ao Curso de Licenciatura em Ciências Biológicas do Instituto Federal de Educação, Ciência e Tecnologia do Ceará (IFCE) - Campus Acaraú, como requisito parcial para a obtenção do Título de Licenciada em Ciências Biológicas, e os envolvidos nesta pesquisa tiveram a garantia de que sua identidade seria mantida em sigilo e nenhuma informação seria dada a outras pessoas que não fossem parte da equipe de pesquisadores. Na divulgação dos resultados deste estudo, os nomes dos participantes foram mantidos em sigilo.

\subsection{Procedimentos de Campo}

Para iniciar a pesquisa, foi necessário estabelecer uma relação de confiança mútua entre o pesquisador e os informantes. A proposta de pesquisa foi apresentada aos guias (motoristas) e expostos os objetivos; procedimentos metodológicos e as perspectivas de repercussão dos resultados.

A principal fonte da coleta de dados para obtenção dos resultados foi a aplicação de questionários e entrevistas com os guias (motoristas), turistas e gestores, questionando-os quanto à percepção da diversidade em seu ambiente de trabalho e sobre a espécime em estudo, o Mangue de Botão (Conocarpus erectus).

Os gestores, presidente da cooperativa e chefe da unidade de conservação, foram entrevistados com o intuito de verificar os pontos relacionados à fiscalização; organização das rotas; ao desempenho dos guias (motoristas); nível de conhecimento sobre a espécie Mangue de Botão (Conocarpus erectus); e as contribuições das cooperativas para o Parque Nacional de Jericoacoara.

Seguindo os procedimentos metodológicos deste estudo, foram aplicados na Praia do Preá, município de Cruz/CE, 30 questionários, com os guias (motoristas) vinculados à Cooperturpreá. Ao aplicar os questionários, nosso principal objetivo foi traçar o perfil dos guias (motoristas) e aferir o nível de conhecimento ecológico sobre a vegetação do Parque, mais especificamente sobre o Mangue de Botão (Conocarpus erectus), a Árvore da Preguiça.

As entrevistas com os visitantes foram todas gravadas em áudio, e, posteriormente, transcritas, integralmente, uma a uma, formando, assim, um texto sólido. As perguntas foram feitas de maneira aberta, dando a possibilidade de o entrevistado escolher o caminho que desejasse trilhar. Apesar de existir um roteiro de perguntas previamente elaborado, também foi importante ter a flexibilidade de modificar o curso da conversa, caso fosse necessário e interessante, sem desconsiderar o objetivo da pesquisa.

$\mathrm{Na}$ entrevista com o presidente da cooperativa de transporte turístico, Cooperturpreá, pretendeu-se identificar suas percepções sobre os trabalhos prestados pelos cooperados; entender o processo de inclusão de novas pessoas na cooperativa; bem como saber qual a percepção do presidente sobre a Árvore da Preguiça.

O chefe do Parque Nacional de Jericoacoara relatou suas impressões acerca dos serviços ofertados pelas cooperativas; o nível de conhecimento ecológico dos guias (motoristas) sobre o Mangue de Botão (Conocarpus erectus), e algumas contribuições das cooperativas para o Parque.

A coleta de dados foi realizada considerando o que dizem Weller e Romney (1988), quando orientam que uma pesquisa com 20 a 30 indivíduos é suficiente para definir o domínio cultural de um grupo, pois, a partir daí, as respostas mudam pouco e as informações se repetem. Com esse intuito, a pesquisa foi realizada com os componentes de uma cooperativa que trabalham no transporte de passageiros para a Vila de Jericoacoara, a Cooperturpreá. 
Seguindo a mesma orientação da pesquisa, em Jijoca de Jericoacoara - Ceará, foram realizadas dez entrevistas, com os visitantes que realizaram o passeio do litoral leste com parada na Árvore da Preguiça. As entrevistas pretenderam verificar a satisfação do visitante no local e suas percepções sobre o passeio.

\section{Resultados e Discussões}

A seguir, são apresentados os resultados da pesquisa, seguidos da discussão, que refletem os dados dos sujeitos coletados. Propõe-se, então, uma abordagem dos achados, alinhada com os objetivos propostos pela pesquisa.

\subsection{Sujeitos da Pesquisa - Guias (Motoristas)}

O nível de escolaridade é um fator muito importante e seletivo, que proporciona infinitas vantagens profissionais. Pensando nisso, perguntamos aos guias (motoristas) envolvidos na pesquisa qual o nível de escolaridade cursado. Desses, 3\% indicaram não ser alfabetizados; 3\% têm o Ensino Fundamental incompleto; 7\% apresentaram o Ensino Médio incompleto; e 87\% têm o Ensino Médio completo. Com relação ao gênero, é perceptível que nas cooperativas o representativo masculino é a maioria. Atualmente, $17 \%$ das pessoas vinculadas à cooperativa são do gênero feminino e $83 \%$ são do gênero masculino, um número bastante expressivo, representando quanto o público masculino ainda predomina em algumas profissões.

Quando perguntados sobre o tempo que os cooperados atuam na profissão, 3\% disseram que estão vinculados à cooperativa a pouco menos de 1 ano, e $97 \%$ responderam que estão na cooperativa desde o início de criação. Sobre os recursos financeiros serem ou não satisfatórios, 3\% afirmam que não é satisfatório, enquanto os outros $97 \%$ dizem que são satisfatórios, ou seja, a maior parte dos entrevistados está satisfeita com o ganho recebido, enquanto uma pequena porcentagem está insatisfeita com a renda gerada.

Quando questionados sobre a possibilidade de extinção da espécie Mangue de Botão (Conocarpus Erectus), 47\% declararam que a espécie não será extinta, enquanto $53 \%$ falaram que sim, a espécie pode acabar, levando em consideração que se trata de um atrativo turístico do Parque.

Perguntados se recebem algum tipo de treinamento para atuar como guia (motoristas) do passeio, $100 \%$ disseram que sim, pois todos recebe um treinamento, ao entrar na cooperativa e que os cursos ofertados pela própria cooperativa são Primeiros Socorros e Direção Defensiva e que o ICMBio oferta o curso de Ambiente e Normas de Segurança.

Embora os guias participem de treinamento com o ICMBio, responsável pela gestão do Parque Nacional de Jericoacoara, ficou claro que eles não têm conhecimento do instrumento chamado de Plano de Manejo.

Perguntamos aos guias de turismo sobre os danos da visitação na vegetação do Parque e 100\% dos respondentes disseram que causa, sim, bastante impacto, porém afirmaram que eles tentam passar o máximo de informação para evitar danos maiores na vegetação, especificamente na Árvore da Preguiça. Diante dessas respostas, fica claro que os guias de turismo entendem os impactos que a visitação pode causar na vegetação existente na área.

Com os resultados dos questionários, corroborou que os cooperados tentam utilizar mecanismos que facilitem o conhecimento ecológico sobre a vegetação do Parque e, especificamente, sobre a espécie Mangue de Botão (Conocarpus erectus).

E, nesta perspectiva ecológica, os conhecimentos dos guias (motoristas) estão atrelados ao cooperativismo, ou seja, voltados para os princípios da evolução em conjunto; desta forma, garantem um crescimento igualitário. E desse modo permite o desenvolvimento de novas atividades alternativas e para além disso resgata a cultura e garante o exercício da cidadania, além de promover liberdade e autonomia aos seus cooperados por meio da organização e do trabalho em equipe (Morato \& Costa, 2001, P. 63). 
Desse modo, este questionário teve êxito quando comparado ao objetivo proposto pela pesquisa, pois foi possível aferir o nível de conhecimento ecológico dos guias (motoristas) e ainda observar, nas incursões a campo, que os cooperados têm conhecimento adequado para lidar com as pessoas, ou seja, são capazes de passar informações verídicas sobre a espécie Mangue de Botão (Conocarpus erectus).

\subsection{Sujeitos da Pesquisa - Gestores Presidente da Cooperturpreá e Chefe do Parque Nacional de Jericoacoara}

Nesta seção, estão descritas as percepções dos gestores das unidades pesquisadas, Cooperturprea e Parque Nacional de Jericoacoara, no decorrer da entrevista, que seguiu um roteiro previsto na metodologia do trabalho.

A Cooperativa de Transporte Turístico (Cooperturpreá) fundada em 26 de abril de 2016, e o seu estatuto define como:

“[...] uma sociedade de modo e natureza jurídica própria, na forma da legislação pertinente, de responsabilidade limitada, sendo empresa com fins econômicos, porém sem fins lucrativos, que se rege pelos valores e princípios do Cooperativismo. (COOPERTURPREÁ, Estatuto da cooperativa, 2016)."

O representante da cooperativa Cooperturpreá narrou que o grupo previamente foi iniciado apneas com 40 cooperados e, desde então, realiza viagens para Fortaleza e locais circunvizinhos. Ainda informou que os membros da cooperativa fazem cursos preparatórios de primeiros socorros e direção defensiva, ofertados pela própria cooperativa. Além desses cursos, o ICMBio, responsável pela administração do Parque Nacional de Jericoacoara, também oferece o curso de Ambiente e Normas de Segurança.

As entrevistas aplicadas aos gestores das unidades foram bem similares, com o propósito de efetuar um paralelo com as informações apresentadas por ambos. Diante disso, passamos, agora, para as percepções do chefe do Parque Nacional de Jericoacoara, que, em alguns momentos, complementa as informações dadas pelo presidente da Coopertur preá.

Quando abordamos a questão dos passeios no território do Parque e como acontece o processo de fiscalização, o chefe da UC alegou que os veículos de transporte turístico (exceto quando estão realizando transfer) são abordados e é verificada a conformidade da operação em relação ao que está definido na Portaria 08/2016.

Com relação às ações das cooperativas voltadas para a conservação do Parque de Jericoacoara, o chefe da UC disse que, eventualmente, alguns prestadores de serviço contribuem com mutirões de limpeza do Parque Nacional, mas em número muito reduzido.

Diante dos fatos, argumenta- se que, a partir dos relatos dos gestores, podemos entender que as entrevistas atenderam de modo satisfatório à pesquisa.

\subsection{Sujeitos da Pesquisa - Visitantes}

Um grupo de visitantes que realizou o passeio pelo litoral leste do Parque de Jericoacoara foi entrevistado com o intuito de analisar a percepção deles sobre o passeio e as informações dadas pelos guias (motoristas) a respeito da Árvore da Preguiça.

Com relação ao parâmetro de idade, foi bem variado, visto que cada visitante apresentou uma idade diferente, porém, todos na faixa etária de 20 a 50 anos. As entrevistas com pessoas de diferentes idades possibilitaram extrair respostas que retrataram visões diferenciadas sobre o passeio.

O grupo de respondentes teve a seguinte configuração: 50\% do gênero masculino e 50\% do gênero feminino, visto que foram feitas dez entrevistas com os visitantes que realizaram o passeio até a árvore. 
Sobre o nível escolaridade, o público que realizou o passeio até a Árvore da Preguiça apresentou o seguinte resultado: nenhum com nível fundamental; 10\% com Ensino Médio incompleto; 50\% com o Ensino Médio completo; e 40\% com nível superior. Essa informação é importante para ser traçado o perfil dos visitantes.

O grupo de visitantes entrevistados era oriundo de diferentes locais: Parnaíba/PI, Curitiba/PR, Manaus/AM, Fortaleza/CE e Jijoca de Jericoacoara/CE; grande parte dos entrevistados estava em grupos de amigos e/ou familiares, e um deles estava com o cônjuge.

Questionados sobre a percepção relativa ao passeio, as respostas foram diversas. Alguns disseram que acharam o lugar encantador, prazeroso e classificaram o ambiente como agradável e paradisíaco. Percebe-se que todos as reações relacionadas a essa pergunta foram positivas, pois os visitantes mostraram-se satisfeitos e encantados com o cenário local.

Ao serem questionados se recomendariam o passeio para outras pessoas, todas responderam que sim. Um dos visitantes ressaltou:

"Pois é uma viagem incrível, com um cenário visual bonito de se ver, um lugar encantador, não teriam como não recomendar, tudo perfeito, e para além disso é um passeio turístico bastante rico de conhecimento. (Visitante - Cidade de Parnaíba, 2019).”

Diante disso, é cabível dizer que é de suma importância a hospitalidade na atividade turística, por ser um elemento fundamental para garantir o retorno dos visitantes a um destino turístico, e constatado no tratamento dado aos clientes, que consiste em receber bem, com um bom relacionamento interpessoal. Segundo Camargo (2004), a hospitalidade é um componente necessário ao desenvolvimento do turismo, dentro de qualquer destinação que busque servir com qualidade os visitantes e outros viajantes de um dia.

Ao serem perguntados se era a primeira vez que realizava o passeio até a Árvore da Preguiça (Conocarpus erectus), a maioria respondeu que estava ali pela primeira vez, enquanto $20 \%$ já havia visitado em outras oportunidades.

Quando questionados se as informações sobre a Árvore da Preguiça (Conocarpus erectus) eram novas, ou se já sabiam, para grande parte dos entrevistados foi algo novo, por estarem visitando o local pela primeira vez. Alguns respondentes disseram já ter informações pois já visitara o local em outra oportunidade e outros haviam pesquisado sobre o local, antes da viagem. Todos os entrevistados disseram que gostariam de obter mais informações na parada da Árvore da Preguiça.

Os resultados obtidos denotam que as entrevistas foram relevantes e que a maioria dos guias (motoristas) se encontram preparados para o passeio, contudo aprofundar as informações técnicas sobre o Mangue de Botão é uma necessidade constante.

\section{Considerações Finais}

Levando em consideração a finalidade deste artigo salienta a relevância dos guias (motoristas) para a preservação do Parque Nacional de Jericoacoara - Ceará, este estudo prestou-se aferir o nível de conhecimentos dos guias (motoristas) sobre a espécie Mangue de Botão (Conocarpus erectus) e se havia interferência desse entendimento no processo de conservação da espécie. Esta pesquisa possibilitou verificar que os guias (motoristas), em sua grande maioria, de fato tem um entendimento sobre a espécie Mangue de Botão (Conocarpus erectus) ainda que não se tenham o domínio dos termos técnicos, apresentam conhecimento ecológico sobre a espécie, demonstram conhecimento sobre o ciclo de vida, a floração e a frutificação da espécie, contudo recomenda-se investigar com mais profundidade esse conhecimento ecológico sobre a espécie em estudo. 
Os dados coletados são apenas uma amostra da pesquisa, pois ainda são necessários mais estudos para, de fato, confirmar o nível de conhecimento ecológico dos guias além de averiguar como essas informações são transmitidas para os visitantes e como podem ser multiplicadas e perpetuadas para as futuras gerações.

A da conservação dos atrativos locais é de grande relevância para o desenvolvimento desta pesquisa, que em última instância pode promover maior aprimoramento dos conhecimentos dos guias (motoristas), além de viabilizar a conservação da Árvore da Preguiça (Conocarpus erectus) como atrativo local, e potencializar o turismo sustentável no Parque Nacional de Jericoacoara.

Para pesquisas futuras, partindo desta perspectiva investigativa, na condição de pesquisadora pretende-se contemplar outras cooperativas que atuam no Parque Nacional de Jericoacoara e investigar o conhecimento ecológico de outros elementos da flora da Unidade de Conservação, trabalhando com a possibilidade de gerar material que venha a contribuir para uma interpretação confiável do ambiente em questão.

\section{Referências}

Atlas dos Manguezais do Brasil. Instituto Chico Mendes de Conservação da Biodiversidade. Brasília: Instituto Chico Mendes de Conservação da Biodiversidade, 2018. 176 p.: I. Título

Barbosa, A. G. P., \& Perinotto, A. R. C. Trilha ecológica do cavalo-marinho: Ecoturismo em Barra Grande/PI. ROSA DOS VENTOS - Turismo e Hospitalidade, 2(1).

Begossi A. Extractive reserves in the Brazilian Amazon: anexample to befollowed in the Atlantic forest? Ciência e Cultura 50:2.428.

Borges, A. L. M., \& da Silva, G. B. (2016). Mário Carlos Beni: contribuição para o estudo do turismo. Revista de Turismo Contemporâneo, 4.

Camargo, L. O. D. L. (2004). O desafio da hospitalidade. In Intercom, Anais do XXVII Congresso Brasileiro de Ciências da Comunicação. Intercom,

De la Torre, G. M. V., Pérez, L. M., \& Cárdenas, R. M. (2016). Fatores que determinam o crescimento do turismo em destinos religiosos. Journal of Social Sciences (Ve), 22(1), 85-97.

Dias, R. (2011). Introdução ao Turismo 1. Atlas

Dias, R. (2011). A biodiversidade como atrativo turístico: o caso do Turismo de Observação de Aves no município de Ubatuba (SP). Revista Brasileira de Ecoturismo (RBEcotur), 4(1).

Irving, M. A. Turismo, ética e educação ambiental - novos paradigmas em planejamento In: Irving, M. A., Azevedo, J. Turismo: O desafio da sustentabilidade. Futura.

Maia, R.C, (2016) Manguezais do Ceará/Rafaela Camargo Maia. Recife Imprima 2016.55p.

Martin, G. J. (2001). Etnobotánica, Manual de Métodos: Volumen. 1. Montevideo, Uruguay: Nordan-Comunidad.

Mielke, E. J. C. Cooperativas de turismo: uma estratégia ao desenvolvimento turístico integrado - Análise do roteiro dos imigrantes (Paraná, Brasil). Revista Brasileira de Pesquisa em Turismo, 41, 92-111.

Minayo, M. C. S., Sanches, O. Quantitativo-qualitativo: Oposição ou complementariedade? Cad. Saúde Públ. 9(3), 239-262.

Pereira, B. E., \& Diegues, A. C. (2010). Conhecimento de populações tradicionais como possibilidade de conservação da natureza: uma reflexão sobre a perspectiva da etnoconservação. Desenvolvimento e Meio ambiente, 22.

Pinho, D. B. (1966). Doutrina cooperativa nos regimes capitalista e socialista, suas modificacoes e sua utilidade.

Rodrigues, N. A. A., Gomes Junior, P. P., Silva, M. C., Lima, C. S., Yara, R., Guimarães, E. B., \& Vieira, J. R. Evaluation of embryotoxic and embryostatic effects of the aqueous extract of Rhizophora mangle and tannic acid on eggs and larvae of Aedes aegypti, 90(2), 2141-2148.

Serviço Brasileiro de apoio as micro e pequenas empresas (SEBRAE). Cooperativas: Série empreendimentos coletivos. Sebrae, 2009.

Teixeira, K. D. S. (2008). Propagação de plantas de mangue visando à recuperação de áreas degradadas (Doctoral dissertation, Dissertação (Mestrado em Meio Ambiente e Desenvolvimento) Programa de Mestrado em Meio Ambiente e Desenvolvimento. Universidade Federal de Sergipe. 145p).

Ternes, M. L. F. (2013) Conhecimento ecológico local dos jangadeiros sobre o cavalo-marinho (Hippocampusreidi) e sua relação com a atividade turística no estuário de Maracaípe, Pernambuco, Brasil. UESC.

Weller, S. C., \& Romney, A. K. (1988) Sistematic data collection. Qualitative Research Methods. 10, University of California, Sage publications, 96p. 